PNL-SA-25507

\title{
RADIATION-INDUCED GRAIN BOUNDARY SEGREGATION IN AUSTENITIC STAINLESS STEELS
}

\author{
S. M. Bruemmer \\ L. A. Charlot \\ J. S. Vetrano \\ E. P. Simonen
}

November 1994

Presented at the

Microstructure of Irradiated Materials 1994 Fall

Meeting

November 28 - December 2, 1994

Boston, Massachusetts

Prepared for

the U.S. Department of Energy

under Contract DE-AC06-76RLO 1830

Pacific Northwest Laboratory
Richland, Washington 99352

DISCLAIMER

This report was prepared as an account of work sponsored by an agency of the United States Government. Neither the United States Government nor any agency thereof, nor any of their employees, makes any warranty, express or implied, or assumes any legal liability or responsibility for the accuracy, completeness, or usefulness of any information, apparatus, product, or process disclosed, or represents that its use would not infringe privately owned rights. Reference herein to any specific commercial product, process, or service by trade name, trademark, manufacturer, or otherwise does not necessarily constitute or imply its endorsement, recommendation, or favoring by the United States Government or any agency thereof. The views and opinions of authors expressed herein do not necessarily state or reflect those of the United States Government or any agency thereof.

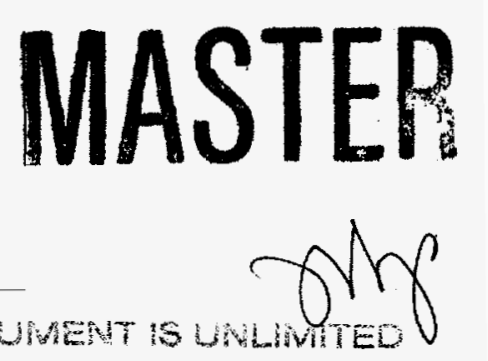




\section{DISCLAIMER}

\section{Portions of this document may be illegible in electronic image products. Images are produced from the best available original document.}




\title{
RADIATION-INDUCED GRAIN BOUNDARY SEGREGATION. IN AUSTENITIC STAINLESS STEELS
}

\author{
S. M. Bruemmer, L. A. Charlot, J. S. Vetrano and E. P. Simonen \\ Pacific Northwest Laboratory, Richland, WA
}

\begin{abstract}
Radiation-induced segregation (RIS) to grain boundaries in Fe-Ni-Cr-Si stainless alloys has been measured as a function of irradiation temperature and dose. Heavyion irradiation was used to produce damage levels from 1 to 20 displacements per atom (dpa) at temperatures from 175 to $550^{\circ} \mathrm{C}$. Measured $\mathrm{Fe}, \mathrm{Ni}$, and $\mathrm{Cr}$ segregation increased sharply with irradiation dose (from 0. to $5 \mathrm{dpa}$ ) and temperature (from 175 to about $350^{\circ} \mathrm{C}$ ). However, grain boundary concentrations did not change significantly as dose or temperatures were further increased. Although interfacial compositions were similar, the width of radiation-induced enrichment or depletion profiles increased consistently with increasing dose or temperature. Impurity segregation (Si and $\mathrm{P}$ ) was also measured, but only $\mathrm{Si}$ enrichment appeared to be radiation-induced. Grain boundary Si peaked at levels approaching 10 at\% after irradiation doses to $10 \mathrm{dpa}$ at an intermediate temperature of $325^{\circ} \mathrm{C}$. No evidence of grain boundary silicide precipitation was detected after irradiation at any temperature. Equilibrium segregation of $P$ was measured in the high- $P$ alloys, but interfacial concentration did not increase with irradiation exposure. Comparisons to reported RIS in neutronirradiated stainless steels revealed similar grain boundary compositional changes for both major alloying and impurity elements.
\end{abstract}

\section{INTRODUCTION}

Radiation-induced segregation (RIS) is a nonequilibrium process that results from the migration of vacancies and interstitials created by displacement damage to various sinks [1]. The incorporation of these point defects into a sink such as a grain boundary induces a change in the alloy composition at the interface. Significant RIS will occur only during specific irradiation conditions of dose rate and temperature. A competition exists among recombination, segregation and back diffusion, as illustrated in Figure 1 for an austenitic stainless steel (SS). Maximum RIS is expected near the center of the RIS region where a high concentration of vacancies and interstitials are being produced and are able to diffuse relatively long distances. The concentration of mobile point defects is believed to decrease at higher temperatures primarily due to an increase in the thermal equilibrium for vacancies, and to decrease at lower temperatures due to restricted defect mobility and enhanced recombination.

Interactions of individual alloying and impurity elements with the defect flow control RIS and dictate the relative change in sink composition. Most grain boundary RIS measurements have been conducted on austenitic SSs because of their use in nuclear reactor core components [2,3]. Grain boundary depletion of $\mathrm{Cr}$ and $\mathrm{Fe}$, and enrichment of $\mathrm{Ni}$ have been attributed to inverse-Kirkendall segregation [4]. This redistribution of major alloying elements is consistent with theirrelative diffusion rates; $\mathrm{Cr}$ diffuses fastest in SS, followed by $\mathrm{Fe}$ and finally $\mathrm{Ni}$. As a result, $\mathrm{Cr}$ and $\mathrm{Fe}$ are more 


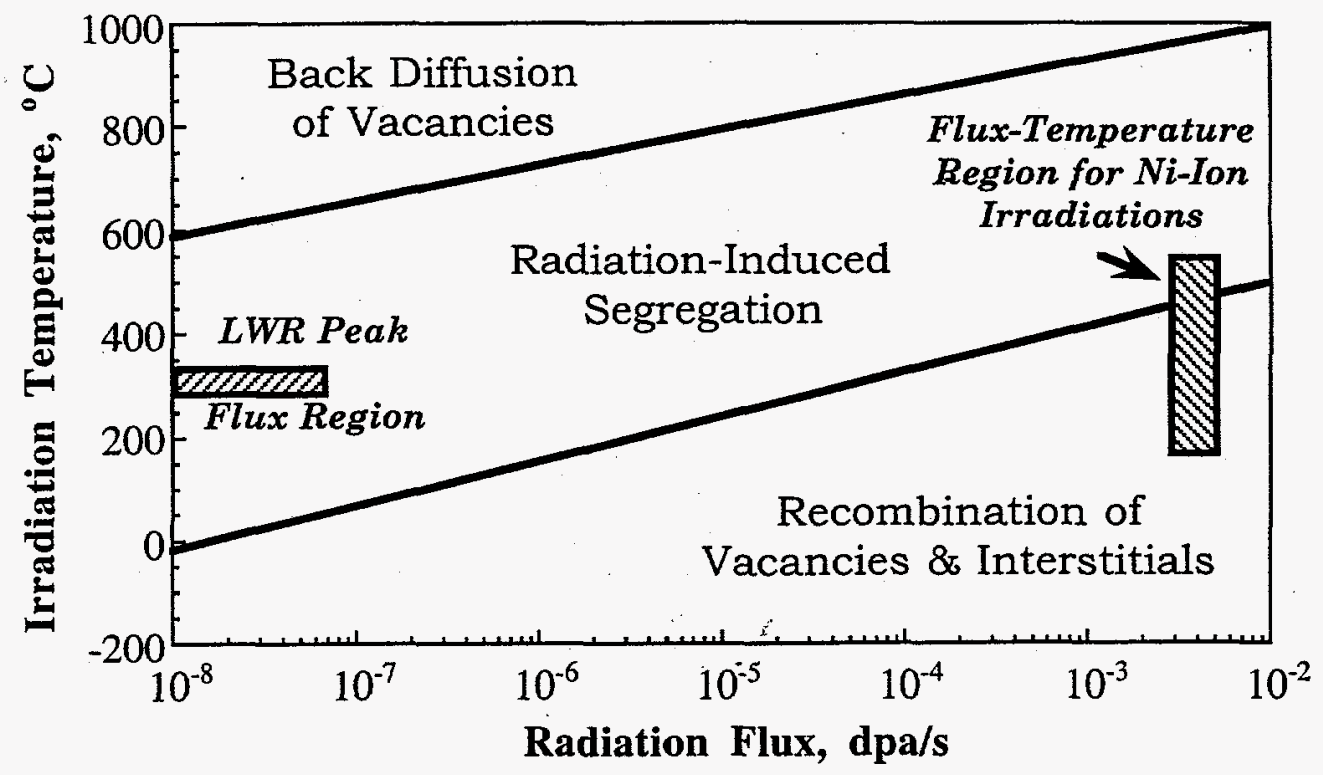

Figure 1. Irradiation Temperature-Flux Diagram for an Austenitic 300-Series SS Illustrating Region Where Radiation-Induced Segregation is Most Pronounced. $[1,2]$

likely to migrate away from the interface (in response to the incoming vacancy flow), leaving $\mathrm{Ni}$ enriched at the boundary. Si and $\mathrm{P}$ have been identified to enrich sinks in SSs. These "undersized" solutes are believed to interact preferentially with interstitials and segregate by an interstitial drag mechanism $[1,5]$.

Although basic mechanisms have been proposed, little quantitative information has been available to evaluate RIS to grain boundaries. Difficulties in working with irradiated materials and limitations in characterization techniques have produced an existing data base that can only suggest trends in segregation behavior. The current work represents a first step to develop a comprehensive RIS data set mapping irradiation temperature and dose effects on the grain boundary composition of $\mathrm{Fe}-\mathrm{Ni}$ $\mathrm{Cr}$ stainless alloys. Analytical transmission electron microscopy (TEM) was used to characterize interfacial compositions and composition profiles in alloys irradiated by heavy ions. A wide range of temperatures $\left(175\right.$ to $\left.550^{\circ} \mathrm{C}\right)$ and dose $(1$ to 20 displacements per atom, dpa) conditions were examined to establish RIS behavior. Many grain boundaries were interrogated for each condition to document boundary-toboundary anisotropy and to determine relevant averages for quantitative comparisons. Additional experimental results investigating dose and temperature effects on RIS in proton-irradiated SS [6], as well as RIS comparisons to model predictions [7], are given in companion papers within these proceedings.

\section{EXPERIMENTAL PROCEDURE}

\section{Materials}

RIS was evaluated in a series of ion-irradiated, Fe-Ni-Cr alloys. Primary alloying and impurity element compositions for these alloys are listed in Table 1. Bulk $\mathrm{C}$ and $\mathrm{N}$ levels were less than 0.01 at $\%$ in all alloys except for the $304 \mathrm{~L}$ SS which contained 0.07 at\% $\mathrm{C}$ and 0.31 at\% N. The FeNiCr and FeNiCr+Si alloys were sputter deposited as $0.13-\mathrm{mm}$-thick foil. The higher $\mathrm{Ni}$ concentration was necessary to stabilize the austenite phase in the as-sputtered condition. Both deposits were given a $750^{\circ} \mathrm{C} / 1-\mathrm{h}$ heat treatment to stabilize a grain size of $\sim 0.5 \mu \mathrm{m}$. A detailed description of the 
TABLE 1. Compositions of Stainless Alloys Used for RIS Studies, at\%

$\begin{array}{cccccc}\text { Alloy } & \underline{\mathrm{Ni}} & \underline{\mathrm{Cr}} & \underline{\mathrm{Mn}} & \underline{\mathrm{Si}} & \underline{\mathrm{P}} \\ \mathrm{FeNiCr} & 20.1 & 19.0 & 1.5 & 1.1 & 0.08 \\ \mathrm{FeNiCr}+\mathrm{Si} / \mathrm{P} & 20.7 & 19.1 & 1.5 & 2.1 & 0.12 \\ \text { 304L SS } & 8.4 & 19.7 & 1.8 & 0.9 & 0.04 \\ \text { UHP } & 8.9 & 20.7 & 1.1 & 0.09 & 0.01 \\ \mathrm{UHP}+\mathrm{Si} & 8.6 & 20.4 & 1.3 & 0.87 & <0.01\end{array}$

production of these fine-grained stainless alloys, and their microstructures, is given elsewhere $[8,9]$. The 304 LSS is, a commercial alloy cold rolled and heat-treated at $900^{\circ} \mathrm{C}$ to stabilize a grain size of $\sim 30 \mu \mathrm{m}$, while the UHP and UHP+Si alloys are ultrahigh-purity laboratory heats [10] with a grain size of $\sim 10 \mu \mathrm{m}$.

\section{Ion Irradiation}

To minimize compositional and structural effects of the embedding atoms, $5 \mathrm{MeV}$ $\mathrm{Ni2}+$ ions were used for ion bombardment. Prior to irradiation, 3-mm-diameter discs were lightly abraded and given an electrochemical polish (in a solution of $5 \%$ perchloric acid in methanol at $\left.-35^{\circ} \mathrm{C}\right)$. Discs were irradiated under vacuum $\left(<5 \times 10^{-6}\right.$ $\mathrm{Pa})$ at a dose rate of 3 to $5 \times 10^{-3} \mathrm{dpa} / \mathrm{s}$. Detailed information concerning the accelerator facility and the irradiation procedure has been previously reported [8]. A standard dose of $10 \mathrm{dpa}$ was employed to map irradiation temperature $\left(175\right.$ to $\left.550^{\circ} \mathrm{C}\right)$ effects on RIS. The flux-temperature range studied is shown in Figure 1 and lies primarily in the region predicted to be recombination-dominated. Dose effects were also examined at selected temperatures ranging from 1 to $20 \mathrm{dpa}$.

\section{Grain Boundary Composition Measurements}

Elemental compositions across grain boundaries were measured in a Vacuum Generators HB501 field-emission-gun, scanning transmission electron microscope (FEG-STEM) with an energy dispersive $x$-ray spectrometer (EDS). Sample preparation was done by electrochemical jetting and polishing in a 5 vol\% perchloric acid-methanol solution cooled to $-40^{\circ} \mathrm{C}$. STEM-EDS analysis was obtained using a 2$\mathrm{nm}$ incident probe and for foil thicknesses from 50 to $75 \mathrm{~nm}$. This resulted in a through-thickness resolution generally less than $4 \mathrm{~nm}$. To ensure that boundary-toboundary variability was accounted for and a reasonable average composition was obtained, more than 10 high-angle grain boundaries were examined for each material condition. Multiple analyses were also made along individual grain boundaries to assess the reproducibility of the composition measurement.

\section{RESULTS AND DISCUSSION}

\section{FEG-STEM Measurement of RIS}

The number of reported measurements of RIS at grain boundaries has increased over the last few years, but still remains limited. Most investigators have used FEGSTEM and EDS techniques to identify $\mathrm{Ni}, \mathrm{Si}$, and $\mathrm{P}$ enrichment, along with $\mathrm{Cr}$ and $\mathrm{Fe}$ depletion, in commercial 300-series SSs. Heavy-ion, proton, electron, and neutron 
irradiations have shown that RIS is very localized (within several nanometers) at grain interfaces. Accurate assessment of RIS characteristics is difficult because very few $(\sim 2)$ grain boundaries are typically examined. The current measurements on the finegrained stainless alloys enable a large number of grain boundaries to be analyzed and a statistically relevant determination of RIS to be made.

\section{Boundary-to-Boundary RIS Anisotropy}

Interfacial composition was discovered to be significantly different among the 10 to 20 high-angle grain boundaries analyzed per irradiation condition. Examples of boundary-to-boundary variability in $\mathrm{Cr}$ and $\mathrm{Si}$ concentrations are shown in Figures 2 and 3 for the $\mathrm{FeNiCr}$ alloy. Clear differences in the measured boundary compositions can be seen in the Figure 2 histograms for $350^{\circ} \mathrm{C} / 10$-dpa and $400^{\circ} \mathrm{C} / 10$-dpa specimens. Cr levels range from about 10 to 16 at\% and 7 to 14 at $\%$ at 350 and $400^{\circ} \mathrm{C}$, respectively. Similar variability was observed for $\mathrm{Ni}, \mathrm{Fe}$, and $\mathrm{Si}$ concentrations in the irradiated specimens. Full $\mathrm{Cr}$ and $\mathrm{Si}$ profiles for a $400^{\circ} \mathrm{C} / 10$-dpa specimen plotted in Figure 3 demonstrate that both the interfacial composition and the width of the depleted or enriched region varies among the boundaries. This anisotropy was identified in all irradiated specimens in which significant RIS occurred.

To ensure that measured compositional differences were due to differences among individual boundaries, multiple measurements along individual interfaces were recorded, as illustrated in Figure 4 . Detectable $( \pm 1.5$ at $\%)$ changes in elemental compositions were measured with position along a grain boundary, but these were much less than that identified among different boundaries. Care was taken to avoid any significant analysis-technique changes known to affect measurement resolution, such as foil thickness and boundary tilt. Current results indicate that RIS depends on individual boundary characteristics, as does equilibrium segregation. Lower RIS was observed at incoherent twin boundaries, and very little segregation was seen at coherent twins.

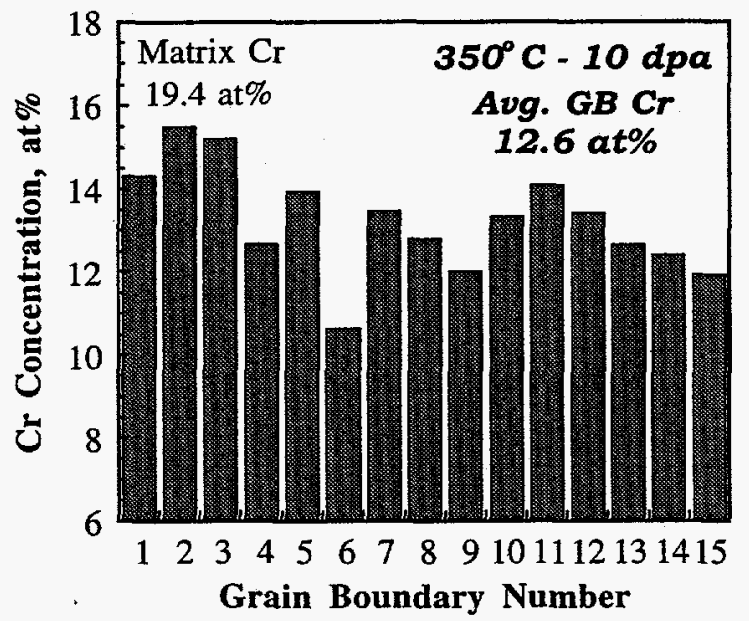

(a)

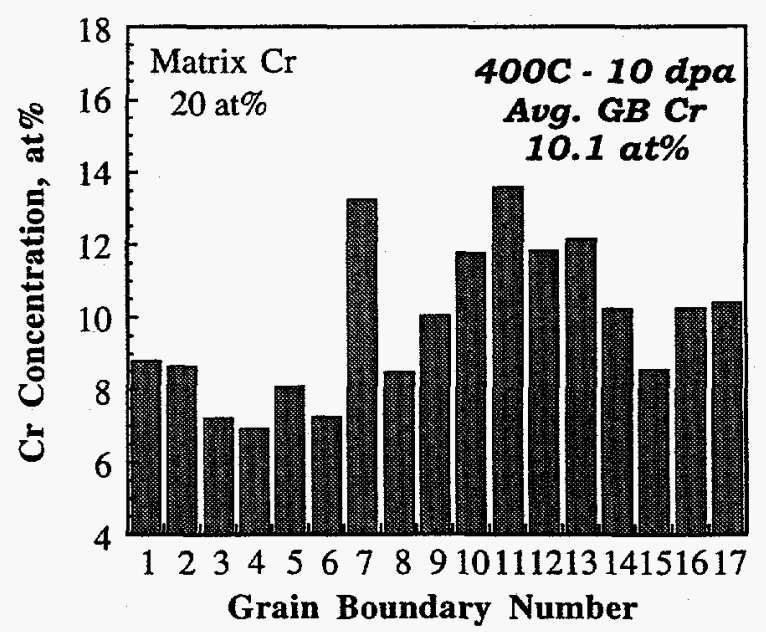

(b)

Figure 2. Grain Boundary Cr Composition Histograms for $350^{\circ}$ (a) and $400^{\circ} \mathrm{C}$ (b) Irradiations Showing Boundary-to-Boundary Differences Measured in the Ni-Ion Irradiated FeNiCr Alloy. 

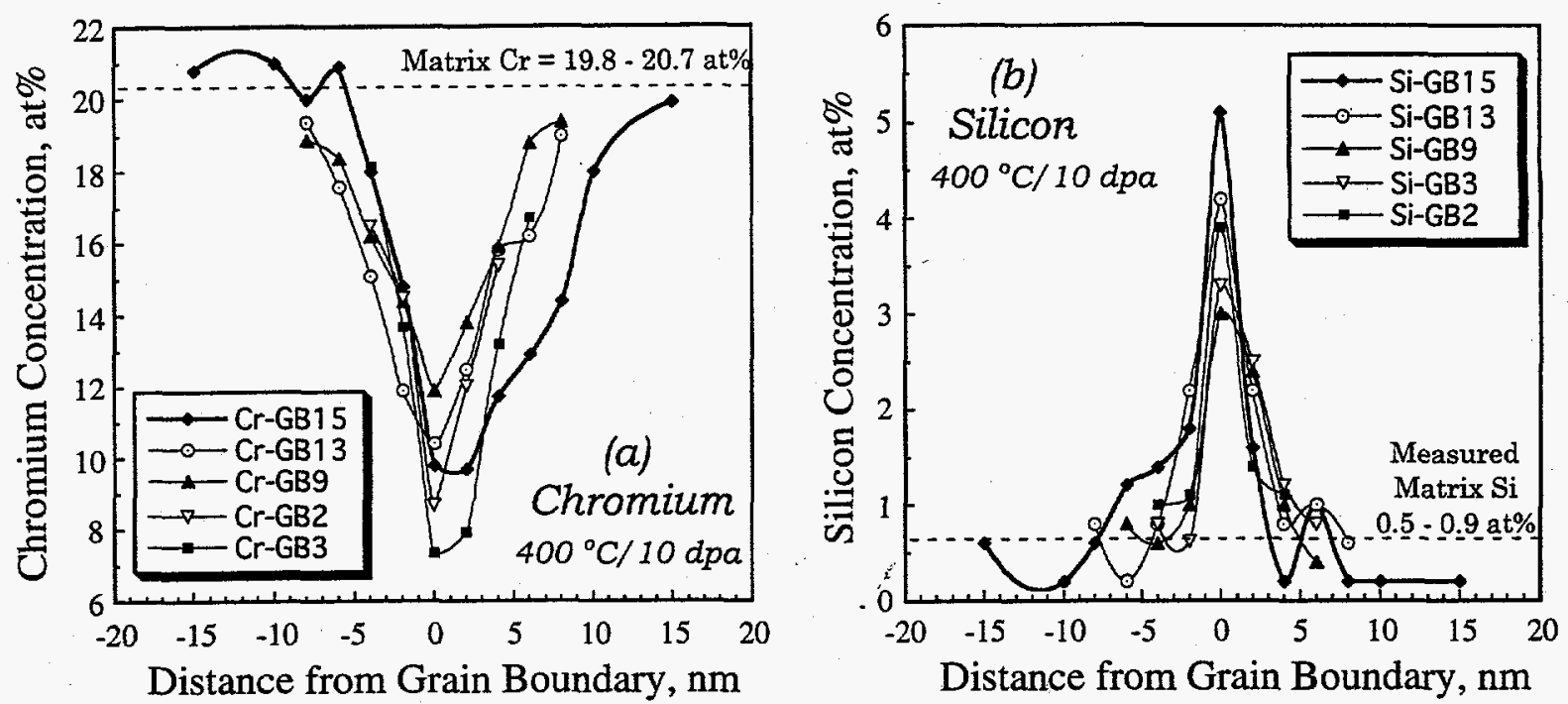

Figure 3. STEM-EDS Measured Composition Profiles for $\mathrm{Cr}$ (a) and $\mathrm{Si}$ (b) Across Various High-Angle Grain Boundaries in the Ion-Irradiated FeNiCr Alloy.

\section{Grain Boundary Segregation in Ion-Irradiated Stainless Alloys}

Average compositions at high-angle grain boundaries have been determined and used to investigate dose and temperature effects on RIS. Enrichment of $\mathrm{Ni}$ and $\mathrm{Si}$ and depletion of $\mathrm{Cr}$ and $\mathrm{Fe}$ was detected in each alloy after irradiation. Comprehensive experiments were performed on fine-grained FeNiCr alloys to examine a wide range of irradiation doses ( 1 to $20 \mathrm{dpa}$ ) and temperatures $\left(175\right.$ to $550^{\circ} \mathrm{C}$ ). RIS was found to increase with dose and reach maximum interfacial enrichment or depletion at intermediate temperatures. Selected irradiations were also performed on commercial and high-purity 304 SSs to compare to the higher Ni stainless alloys.

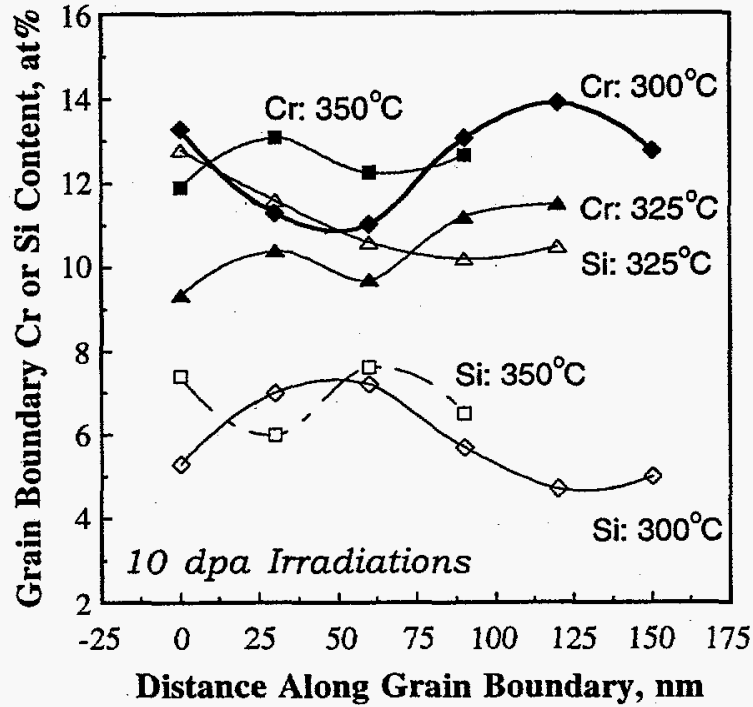

Figure 4. Measured Variations in $\mathrm{Cr}$ and Si Concentration Along High-Angle Grain Boundaries in the FeNiCr Alloy.

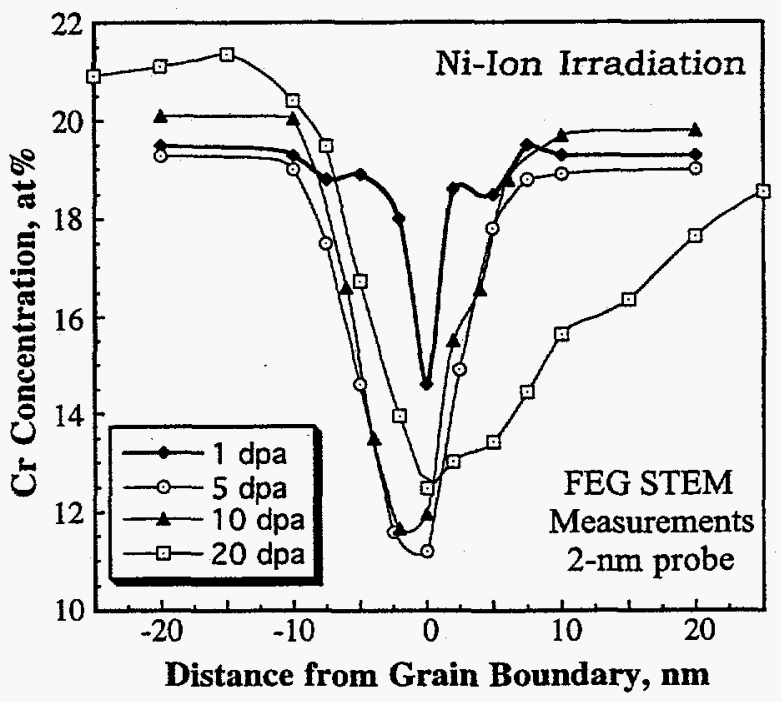

Figure 5. Typical Cr Composition Profiles after Ion Irradiation at $500^{\circ} \mathrm{C}$ to Doses from 1 to $20 \mathrm{dpa}$. 


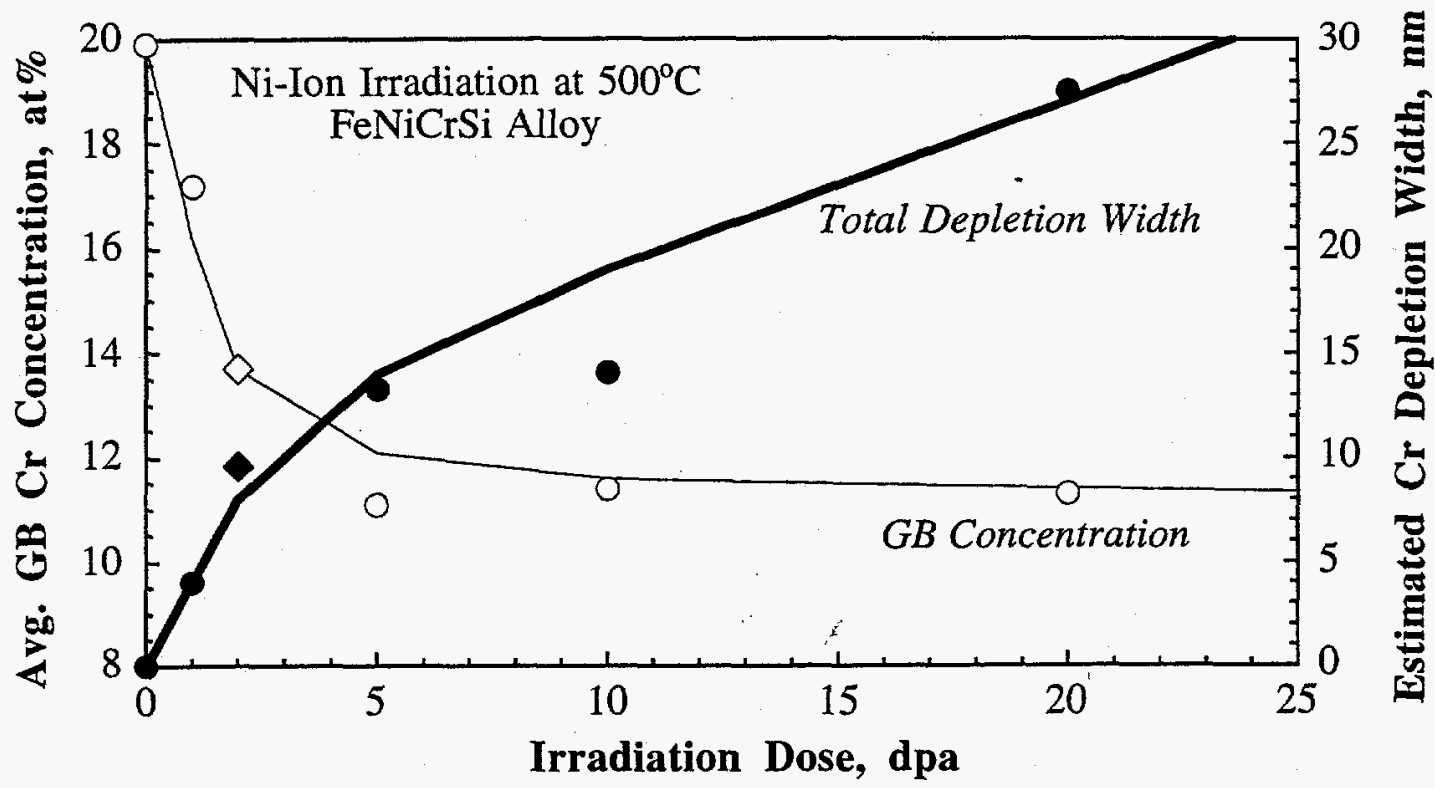

Figure 6. Dose Effects on the Average Grain Boundary Cr Depletion.

\section{Major Alloying Element Segregation}

Dose effects on the grain boundary $\mathrm{Cr}$ concentration and the width-of-depletion profile is shown in Figures 5 and 6 for an irradiation temperature of $500^{\circ} \mathrm{C}$. Measured $\mathrm{Cr}$ levels dropped sharply over the first few dpa and then changed very little at doses exceeding $5 \mathrm{dpa}$. Depletion width, on the other hand, increased with dose over the full range examined. Similar changes in boundary concentrations and near-boundary gradients were established for $\mathrm{Ni}$ and $\mathrm{Fe}$. Interfacial $\mathrm{Ni}$ nearly doubled with irradiation from $\sim 22$ to 40 at\%, while Fe decreased from $\sim 53$ to 42 at\%. As for $\mathrm{Cr}$, the most significant change after increasing dose from 5 to $20 \mathrm{dpa}$ was in the width of the RIS profile. Limited variable dose exposures at 300 and $400^{\circ} \mathrm{C}$ reveal dose-dependent RIS in agreement with that documented at $500^{\circ} \mathrm{C}$.

A strong influence of irradiation temperature on RIS was discovered. Little change in grain boundary concentrations was detected in specimens irradiated to a dose level of $10 \mathrm{dpa}$ at temperatures below $200^{\circ} \mathrm{C}$. RIS increased rapidly with temperature up to $\sim 300^{\circ} \mathrm{C}$, as illustrated for $\mathrm{Cr}$ and $\mathrm{Ni}$ in Figure 7. Grain boundary $\mathrm{Cr}$ dropped sharply from 18 at $\%$ at $175^{\circ} \mathrm{C}$ to 13 at $\%$ at $300^{\circ} \mathrm{C}$, while $\mathrm{Ni}$ rose from 22 to 40 at $\%$. Surprisingly, $\mathrm{Cr}$ did not continue to significantly decrease, or Ni levels increase, at higher temperatures. Interfacial $\mathrm{Cr}$ and $\mathrm{Ni}$ concentrations showed some scatter at temperatures from 300 to $550^{\circ} \mathrm{C}$, but remained at $\sim 12$ and $\sim 39$ at $\%$, respectively. Although boundary concentrations were comparable, profile widths increased over the entire range of temperatures examined. For example, $\mathrm{Cr}$ depletion widths nearly doubled between 275 and $400^{\circ} \mathrm{C}$, and then doubled again between 400 and $550^{\circ} \mathrm{C}$. RIS characterizations on the lower-Ni 304 SSs after irradiations at 250 and $500^{\circ} \mathrm{C}$ also indicated this strong effect of temperature and showed slightly less RIS (Figure 7).

\section{Impurity Segregation}

Si was consistently observed to enrich grain boundaries due to irradiation. Average $\mathrm{Si}$ interfacial composition in the $\mathrm{FeNiCr}$ alloy increased with irradiation dose at $500^{\circ} \mathrm{C}$, reaching $\sim 7$ at\% at high dose levels, as shown in Figure 8 . The width of the measured enrichment profile also increased with dose, but remained somewhat narrower than for 


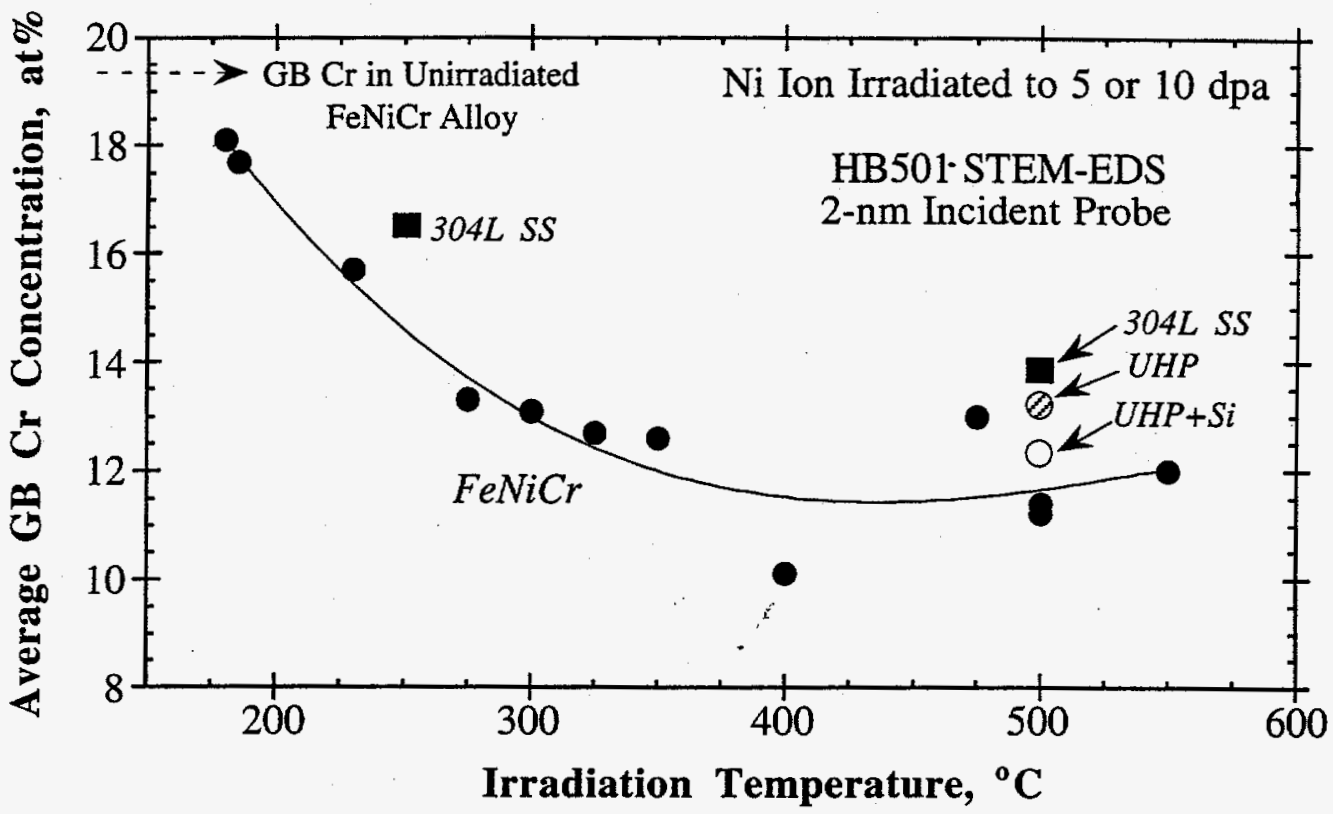

Figure 7. Irradiation Temperature Effects on the Grain Boundary Cr Concentration. Most Irradiations at to a Dose of $10 \mathrm{dpa}$ Except for Several Points at $500^{\circ} \mathrm{C}$.

$\mathrm{Cr}$. Consistent with the measured major alloying element segregation, Si RIS was found to be a strong function of temperature (Figure 9). Grain boundary Si levels peaked at $\sim 8$ at $\%$ at $325^{\circ} \mathrm{C}$ for the 10-dpa exposures, and dropped to 7 at $\%$ or less at 400 to $550^{\circ} \mathrm{C}$. The maximum Si composition measured at any grain boundary was $\sim 13$ at $\%$ in the $325^{\circ} \mathrm{C} / 10$-dpa sample. TEM characterization of this and other segregated boundaries revealed no evidence of second-phase (i.e., $\mathrm{Ni}_{3} \mathrm{Si}$ ) precipitation in any of the stainless alloys. High-dose (10-dpa) irradiations on the $\mathrm{FeNiCr}+\mathrm{Si} / \mathrm{P}$ alloy (Si about $2 \mathrm{x}$ higher) showed interfacial $\mathrm{Si}$ enrichments similar to the $\mathrm{FeNiCr}$ alloy, as did the UHP+Si alloy irradiated at $500^{\circ} \mathrm{C}$.

$\mathrm{P}$ segregation was not consistently observed at boundaries in the irradiated $\mathrm{FeNiCr}$ alloy, even though it was present at high levels $(\sim 0.08$ at $\%)$ in the bulk. Maximum

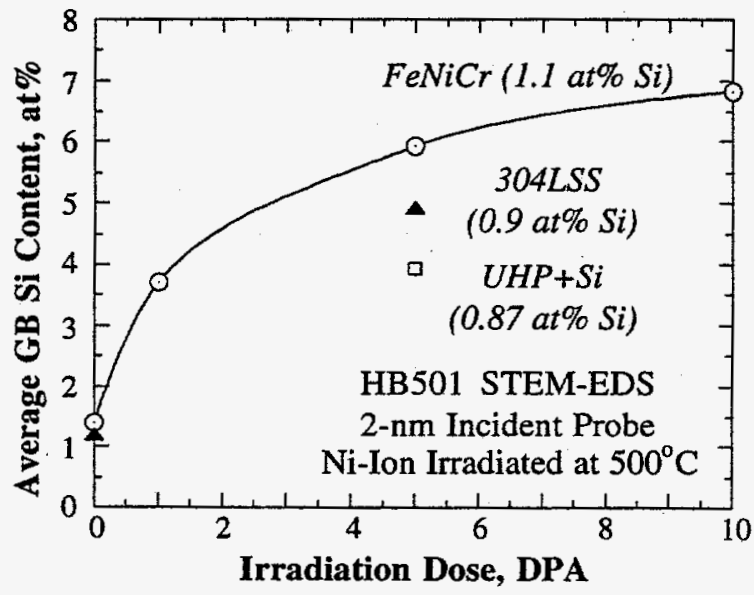

Figure 8. Influence of Irradiation Dose on the Grain Boundary Silicon Concentration.

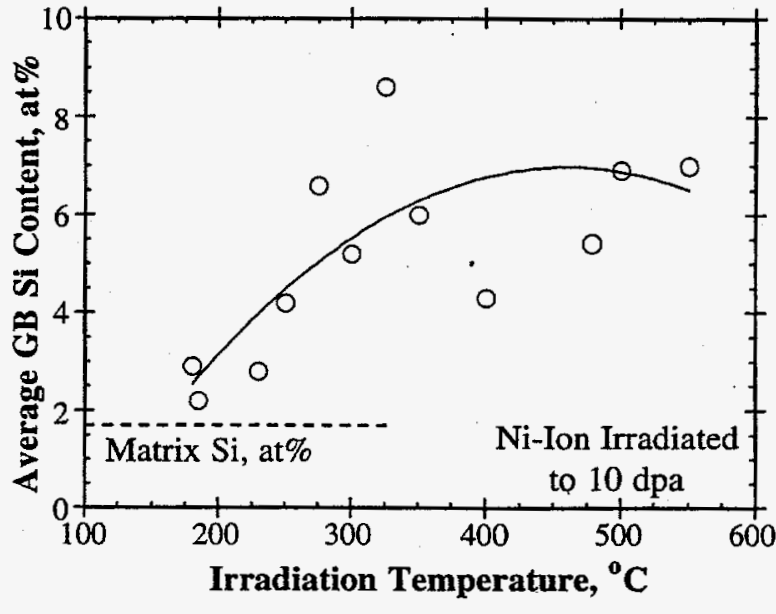

Figure 9. Irradiation Temperature Effects on the Grain Boundary Silicon Content. 


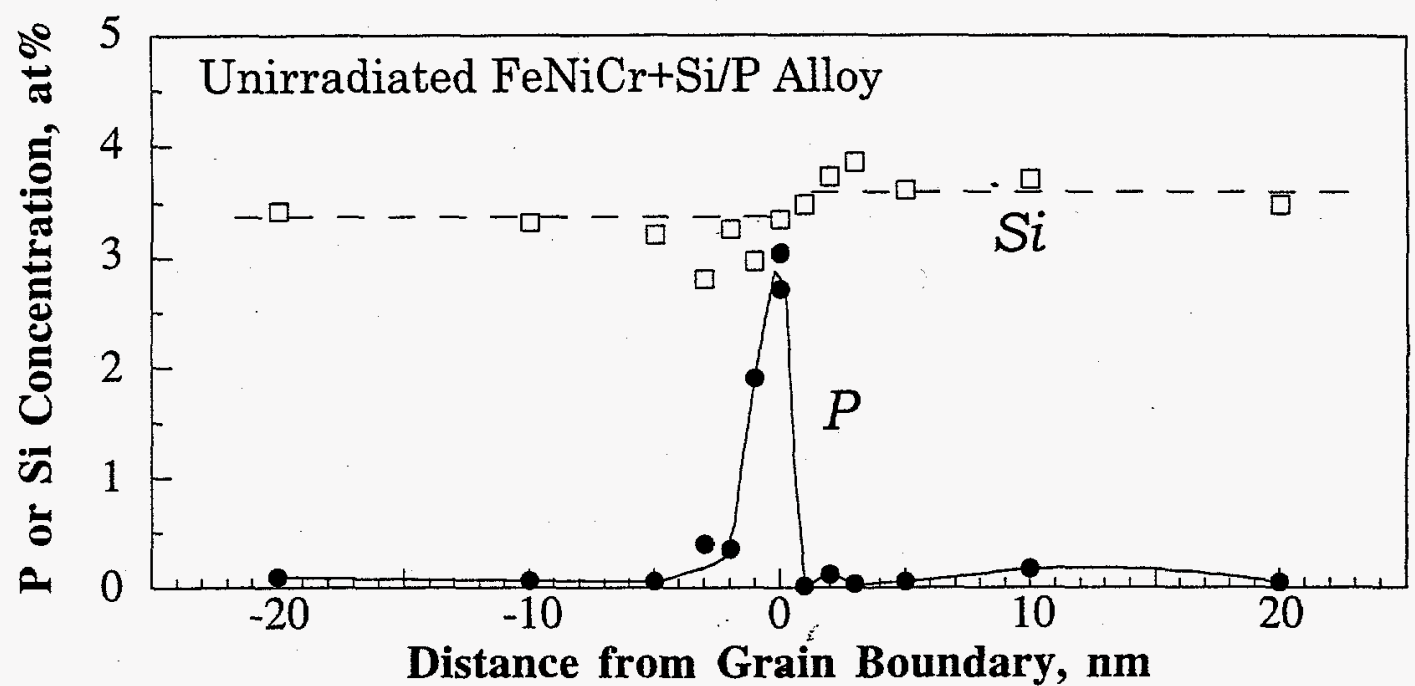

Figure 10. Measured P and Si Concentration Profiles Across Grain Boundaries in Unirradiated $\mathrm{FeNiCr}+\mathrm{Si} / \mathrm{P}$ Alloy Heat Treated at $750^{\circ} \mathrm{C}$ for $1 \mathrm{~h}$.

concentrations were less than 0.7 at $\%$ at any boundary regardless of irradiation dose or temperature. Most boundaries showed levels near the EDS resolution limit ( 0.4 at\%) for. P. No consistent differences in $\mathrm{P}$ were observed as a function of dose or temperature. However, equilibrium segregation of $P$ was detected by FEG-STEM in the unirradiated $\mathrm{FeNiCr}+\mathrm{Si} / \mathrm{P}$ alloy, as illustrated in Figure 10. A maximum concentration of 3 at $\%$ and an average concentration of 1.7 at\% were identified, while no Si segregation was discovered. Irradiations to $10 \mathrm{dpa}$ at temperatures where significant RIS was documented for $\mathrm{Si}, \mathrm{Ni}, \mathrm{Cr}$, and $\mathrm{Fe}$ have not shown any enhanced $\mathrm{P}$ enrichment. In all cases, measured $P$ composition profiles were extremely narrow ( $\leq 3$ $\mathrm{nm}$ ), consistent with FEG-STEM resolution for equilibrium monolayer segregation.

In summary, Si has been shown to enrich grain boundaries as a function of dose and temperature. P, on the other hand, did not exhibit significant RIS. It was present in irradiated SSs, but appeared to result primarily from thermal segregation. Measured grain boundary compositions of $\mathrm{Si}$ in irradiated $\mathrm{SSs}$ were consistently greater than $\mathrm{P}$. FEG-STEM measurements indicated the extent of segregation in the boundary region, but actual interfacial compositions were somewhat greater due to the narrow enrichment profiles in comparison to the technique's through-thickness resolution. This was particularly true for monolayer-type profiles for $P$, in which actual interfacial compositions were estimated to be $\sim 5$ times greater than the FEG-STEM values [10].

\section{Grain Boundary Segregation in Neutron-Irradiated Stainless Steels}

\section{Major Alloying Elements}

Radiation-induced $\mathrm{Cr}$ depletion has been the focus of many IASCC studies because of its well-documented effects in promoting IGSCC in sensitized SSs. Grain boundary $\mathrm{Cr}$ concentrations measured in neutron-irradiated 304,316 and 348 SSs have been compiled [3] and minimum concentrations plotted as a function of fluence in Figure 11. The most detailed characterization of neutron fluence effects on grain boundary RIS has been reported by Jacobs [11] on 304 SSs. A consistent decrease in interfacial $\mathrm{Cr}$ was detected with increasing fluence up to $\sim 2 \times 1021 \mathrm{n} / \mathrm{cm}^{2}$, i.e. about $3 \mathrm{dpa}$. Samples irradiated to slightly higher fluences did not show a continued decrease in the grain 


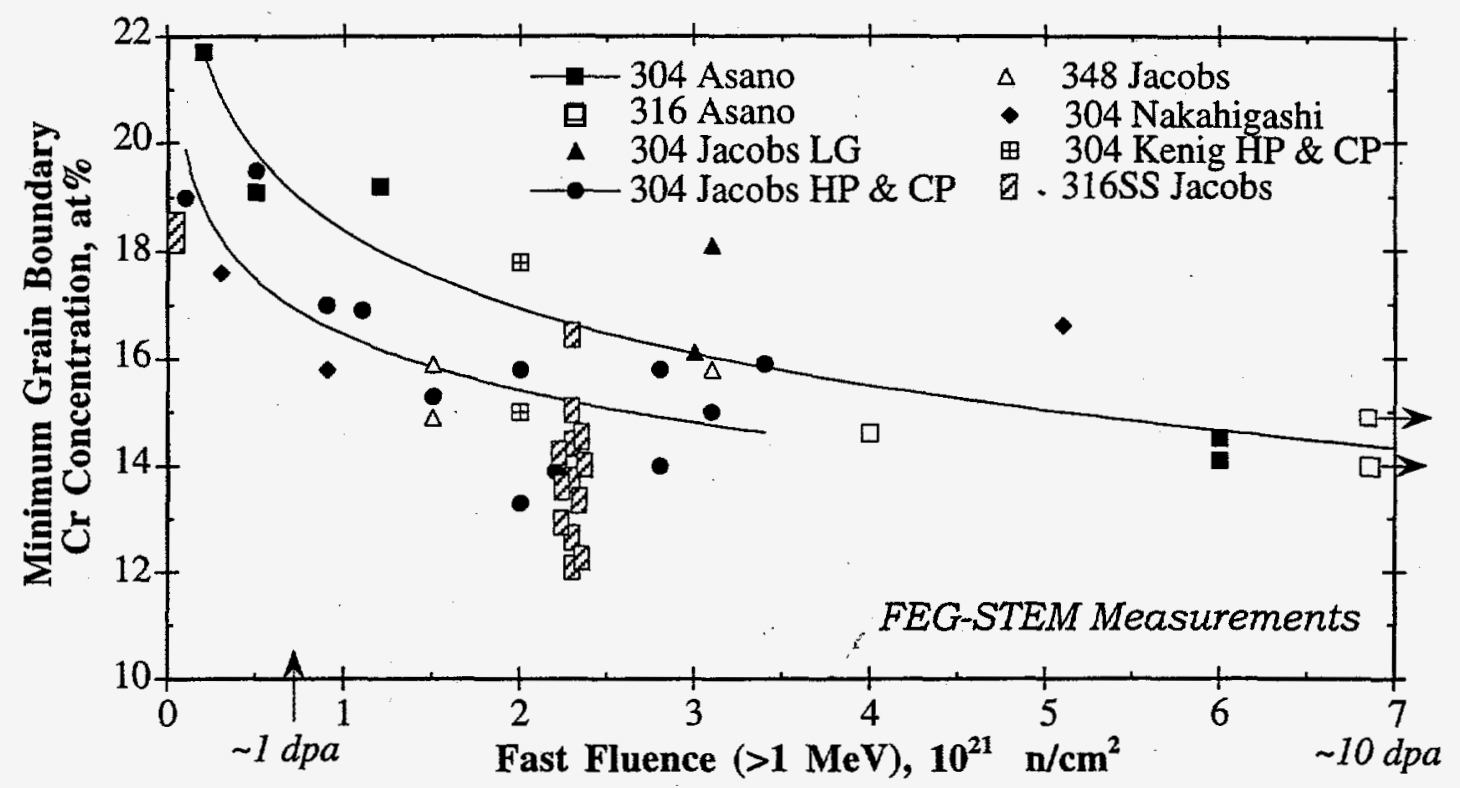

Figure 11. FEG-STEM Measurements of Cr Grain Boundary Concentrations as a Function of Fluence in Neutron-Irradiated Stainless Steels.

boundary $\mathrm{Cr}$ level. This change in the rate of segregation agrees with the ionirradiation dose dependence. Cr enrichment has been reported at low fluence levels, as indicated by the data of Asano, et al. [12] This initial enrichment shifted the fluence dependence curve to higher $\mathrm{Cr}$ concentrations and may require an increased fluence to achieve comparable grain boundary depletion. Considering the wide range of materials and starting conditions, most data showed a consistent exponential decrease in interfacial $\mathrm{Cr}$ content with increasing fluence out to several dpa.

\section{Impurity Segregation}

Bruemmer, et al. [13] recently reviewed measurements of $S i$ and $P$ enrichment at grain boundaries in neutron-irradiated SSs. Si observations are more common because of its high bulk content $(0.7$ to 2.0 at\%) compared to $P(0.01$ to 0.08 at $\%)$. Measured grain boundary concentrations for $\mathrm{Si}$ appear to increase with fluence (Figure 12a) and reach levels of about $6-8$ at\% at a moderate dose of $\sim 2.2 \times 1021 \mathrm{n} / \mathrm{cm}^{2}$; i.e., 3 dpa. Very few FEG-STEM measurements are available at higher doses to determine if segregation levels continue to increase. However, Ni-silicide precipitation has often been observed at dislocation loops and boundaries in SSs irradiated at higher temperatures $\left(>380^{\circ} \mathrm{C}\right)$ and to higher doses (>20 dpa).

The few measurements of grain boundary $P$ in neutron-irradiated SSs do not show any clear indication of RIS. Interfacial compositions range from not detectable $(<0.4$ at\%) to $\sim 3$ at\% regardless of dose, as shown in Figure 12(b). Such variability may result from differences in $\mathrm{P}$ segregation before irradiation. $\mathrm{P}$ strongly segregates to grain boundaries in both $\mathrm{Fe}$ - and Ni-base stainless alloys during thermal treatments approaching levels of several at\% in the solution-annealed condition. Unfortunately, unirradiated archive materials are rarely characterized and compared to results on neutron-irradiated samples.

Measurements of RIS in neutron-irradiated SSs are in qualitative agreement with the heavy-ion results for both major alloying elements and impurities. $\mathrm{Cr}$ and $\mathrm{Si}$ 


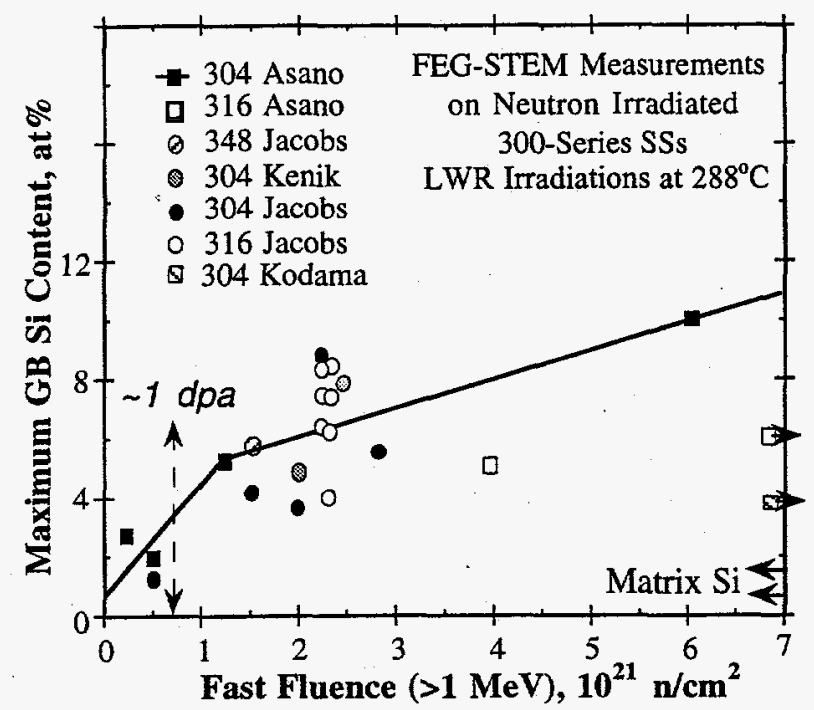

(a)

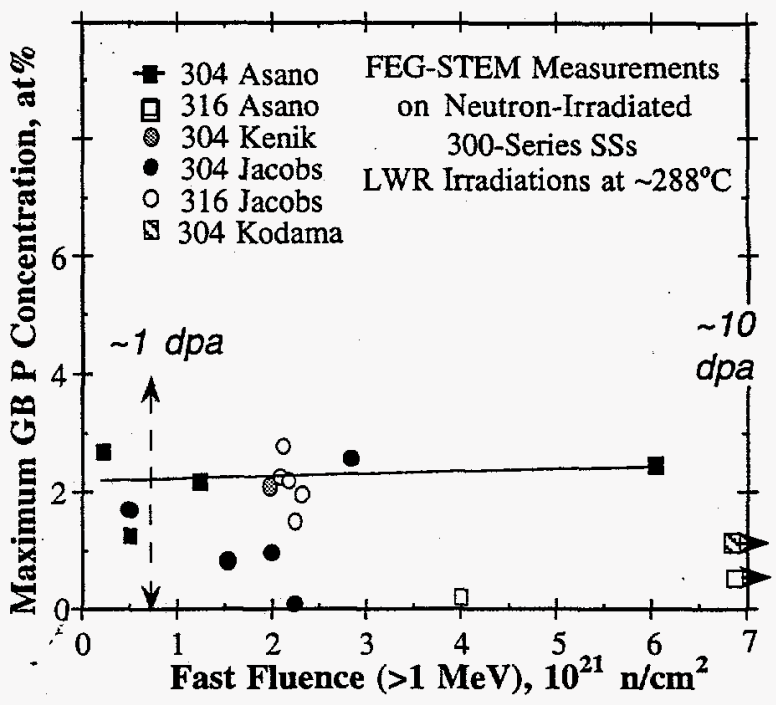

(b)

Figure 12. FEG-STEM Measurements of $\mathrm{Si}(\mathrm{a})$ and $\mathrm{P}$ (b) RIS as a Function of Neutron Fluence in Neutron-Irradiated Stainless Steels.

segregation increases with dose at $288^{\circ} \mathrm{C}$ for neutrons (Figures 11 and 12a), comparable to that at $500^{\circ} \mathrm{C}$ for $\mathrm{Ni}$ ions (Figures 6 and 8). Radiation-induced grain boundary compositions change rapidly with dose and reach similar levels at a moderate dose; e.g., $\mathrm{Cr}$ drops to $\sim 13$ at\% and Si reaches $\sim 6$ at\%. Part of this sharp change in measured interfacial composition with dose at low dpa may result from the narrow width of the RIS profile. The measured boundary composition may be significantly different than the actual composition at low dose because the profile width is smaller than the FEG-STEM resolution. Ion irradiations demonstrate that the width of the segregation profile increases with dose. Results in Figures 6 and 11 indicate that interfacial $\mathrm{Cr}$ compositions do not change as rapidly with dose above $3 \mathrm{dpa}$. The other major alloying elements, $\mathrm{Ni}$ and $\mathrm{Fe}$, follow this same behavior as apparently does $\mathrm{Si}$. The strong RIS observed at temperatures below $300^{\circ} \mathrm{C}$ in the heavy-ion irradiated alloys (Figure 7) suggests that significant RIS is likely at temperatures below $100^{\circ} \mathrm{C}$ in neutron-irradiated stainless steels.

\section{CONCLUSIONS}

Radiation-induced segregation to grain boundaries in $\mathrm{Fe}-\mathrm{Ni}-\mathrm{Cr}-\mathrm{Si}$ stainless alloys was found to increase sharply with irradiation dose (from 0 to $5 \mathrm{dpa}$ ) and temperature (from 175 to about $350^{\circ} \mathrm{C}$ ). However, grain boundary concentrations of major alloying elements stabilized at approximately 12 at\% $\mathrm{Cr}$ and 38 at\% $\mathrm{Ni}$ for higher dose or higher temperature irradiations. Although interfacial compositions were similar, the width of radiation-induced enrichment or depletion profiles increased with increasing dose or temperature. Grain boundary $\mathrm{Si}$ and $\mathrm{P}$ segregation was also measured, but only Si enrichment appeared to be radiation induced. Si reached a maximum content of nearly 10 at $\%$ at an intermediate temperature of $325^{\circ} \mathrm{C}$. Interfacial $P$ levels were comparable in both irradiated and unirradiated materials. Stainless steels neutron irradiated at $288^{\circ} \mathrm{C}$ reveal similar effects of dose on grain boundary compositions of major alloying elements ( $\mathrm{Cr}, \mathrm{Ni}$, and $\mathrm{Fe}$ ) and impurity elements ( $\mathrm{Si}$ and $\mathrm{P}$ ). 


\section{ACKNOWLEDGEMENTS}

Research was supported by the Materials Sciences Branch, Office of Basic Energy Sciences, under Contract DE-AC06-76RLO 1830 with Pacific Northwest Laboratory, a multiprogram laboratory operated by Battelle Memorial Institute.

\section{REFERENCES}

1. P. R. Okamoto and L. E. Rehn, J. Nucl. Mater., 83, 2 (1979).

2. P. L. Andresen, F. P. Ford, S. M. Murphy, and J. M. Perks, in Proc. 4th Int. Sym. Environmental Degradation of Materials in Nuclear Power Systems - Water Reactors, eds. D. Cubicciotti and G. J. Theus (National Association of Corrosion Engineers, Houston, TX, 1990), p. 1-83.

3. S. M. Bruemmer and G. S. Was, J. Nucl. Mater., 216, 326 (1994).

4. J. M. Perks, A. D. Marwick, and C. A. English, A Computer Code to Calculate Radiation-Induced Segregation in Concentrated Ternary Alloys, AERE-R-12121 (Harwell, Oxfordshire OX11 ORA, June 1986).

5. R. A. Johnson and N. Q. Lam, Physical Review B, 13, 4364 (1983).

6. D. L. Damcott, G. S. Was, and S. M. Bruemmer, "Radiation-Induced Segregation in Austenitic Stainless Steel," Materials Research Society, these proceedings.

7. E. P. Simonen and S. M. Bruemmer, "Radiation-Induced Segregation: A Microchemical Gauge to Quantify Fundamental Defect Parameters," Materials Research Society, these proceedings.

8. S. M. Bruemmer, M. D. Merz, and L.A. Charlot, J. Nucl. Mater., 186, 13 (1991).

9. S. M. Bruemmer, L. A. Charlot, B. W. Arey, and M. D. Merz, Irradiation Effects on Grain Boundary Chemistry of Austenitic Stainless Steels, Final Report, Research Project 2680-09 (Electric Power Research Institute, Palo Alto, CA, 1991).

10. R. D. Carter, D. L. Damcott, M. Atzmon, G. S. Was, S. M. Bruemmer, and E. A. Kenik, in Proc. 6th Int. Symp. on Environmental Degradation of Materials in Nuclear Power Systems - Water Reactors. R. Gold and E. P. Simonen, Eds. (TMS, 1993) p. 501.

11. A. J. Jacobs, in 16th ASTM Symp. Radiation Effects on Materials, STP 1175, (American Society for Testing and Materials, Philadelphia, PA, 1992).

12. K. Asano, K. Fukuya, K. Nakata, and M. Kodama, in Proc. 5th Int. Symp. on Environmental Degradation of Materials in Nuclear Power Systems - Water Reactors, D. Cubicciotti, E. P. Simonen and R. Gold, Eds. (American Nuclear Society, 1992) p. 838.

13. S. M. Bruemmer, T. F. Soran, J. I. Cole, B. W. Arey, L. A. Charlot, and C. F. Windisch, Jr., "Radiation-Induced Segregation of Impurities and Effects on the Electrochemistry of Nickel and Stainless Steel," in Corrosion95 (National Association of Corrosion Engineers, 1995) Paper 420, in press. 